\title{
CLASSIFYING VIDEO GAME TRANSLATION STUDIES FROM TRANSTEXTUALITY PERSPECTIVES
}

\author{
SF Lukfianka Sanjaya Purnama \\ iaftersmile@gmail.com \\ SF Luthfie Arguby Purnomo \\ theluthfie@gmail.com \\ IAIN Surakarta
}

\begin{abstract}
This paper attempts to classify video game translation(VGT)studies from the perspectives of transtextuality, Genette's term referring to the relationships a text weaves with other texts (1992). In regard to VGT studies, applying transtextuality signifies the textuality of video game and its transtextual relationship with other texts. Transtextuality is linear to the connectionist perspectives Globalization, Internationalization, Localization, and Translation (GILT) holds, a conventional concept that houses VGT, emphasizing on the intra and inter relationships between the four elements of GILT. This necessity to consider VGT as a part of GILT is the linearity to which transtextuality conforms VGT studies. Applying transtexuality, VGT studies are classified into transversality, transcreation, transfiguration, and transmediation. Transversalityreferstothestudiesaimed at applying translation theories in VGT.Transcreation refers to VGT studies that focus on cultural issues in relation to video game mechanics. Transfiguration refers to VGT studies that incorporate game studies as a response to certain VGT issues. Transmediation refers to VGT studies that focus on the influence of video game media toward the translation aspects of video games. These four classifications construct a quadrant which opens probabilities for VGT studies to depart from the combination of each element.
\end{abstract}

Keywords: transtextuality; video game translation; transversality; transcreation; transfiguration; transmediation

\section{Video Game Translation STUDIES}

Video game translation, henceforth is abbreviated into VGT, as a part of screen translation with its own complex multimodality (O'Hagan 2005), has distinctive features differentiating it from other screen translation such as subtitling, surtitling, dubbing, and voice over. Those distinctive features are (a) spatial constraints, (b) the relationship VGT weaves with Globalization, Internationalization, Localization, and Translation (GILT), (c) gaming experience, and (d) concerns on game aesthetics with the point of departure on ludology and narratology.

Spatial constraints VGT has endow the study a restricted translation, a term proposed by Mangiron \& O'Hagan
(2006). The level of restrictiveness VGT has encompasses not only character number based restrictiveness as found from subtitling but also image restrictiveness. In VGT, violations against character and image restrictiveness might usher not only mechanical and aesthetic problems but also financial costs since extra text and image generate extra data to which extra cost is applied. In mobile game cases, the worst impact of these violations is that extra data might preclude potential customers from downloading the game. Therefore, game translators are required to equip themselves not only with translation ability but also gaming culture, gaming knowledge and computer skills as suggested by Dietz (2012). The 
challenges on VGT translation turn more complicated when spatial constraints are intertwined with the relationship between VGT and GILT.

GILT, as explained by Cadieux and Esselink (2004), situates game translators to orientate their works on localization, internationalization, and globalization from which message transfer should be coordinated with game mechanics and target culture. Buff Studio's Buff Knight, for instance, is translated in Jagoan Jones(lit. Single Thug) to conform to the localization needs of Indonesian gaming culture Purnomo et al. (2016).Buff Knight is an android endless runner game which emphasizes on the game mechanics more than on the game narrative. Localizing the title into Jagoan Jones and stuffing the game with jokes about being single were intended to draw attentions from potential customers and they were proven to work. This transcreation, a rewriting like fashion to fit games for target customers O'Hagan \& Mangiron (2013, 2006) projects the abilities of the game translators in examining and comprehending game mechanics and target culture with GILT as their conceptual framework for their translation. Questions that occur, regarding with the example from Buff Knight, are whether target game share intendedgaming experience like that of the original when translation is executed on the basis of transcreation.

Gaming experience is constructed of video game and puppetry, the interaction between the players and the video games, from which their complete presence would evoke positive experience while the absence of one element would do the opposite (CalvilloGámez, Cairns \& Cox 2015). Due to its structural nature, gaming experience might experience a shift when translation takes place. This is the concern Chandler \& Deming (2011) emphasizes in regard to the fact that games are for international customers with various and diverse gaming culture. Purnomo et al. (2016), departing from the theory that gaming experience is structurally constructed, proposes what is termed as luden, a micro structure that builds video game assets to which translation is applied and from which a shift of gaming experience might occur. In Gameloft's fighting game Gods of Rome, Chaos Vessel, the central object that becomes the primary focus in the game narrative, is translated into BejanaKemelutin its Indonesian version. A shift of luden appears on this translation from which gaming experience might suffer from a shift also. The word chaos might take reference to the primordial Greek deity Chaos from whom night and darkness occur. Meanwhile the word vessel serves not only as reference to a narrative object in the game but also foreshadowing the narrative that Gods of Rome circumnavigates around evil power that possesses and takes the bodies of gods and heroes to battle the player. This narrative luden is shifted when translation is exercised. This narrative luden is shifted when translation is exercised. In the Indonesian version, any reference to the playng of game such DotA (Defense of the Ancients) a custom scenario for the real-time strategy game Warcraft III: Reign of Chaos has been replaced by Mafia Wars, a phenomenon sweeping other locations such as Singapore and Melbourne (Hjorth 2011). In the Indonesian version, any reference to Chaos is absent and vessel with its alluded meaning is alsountransferable. In game aesthetics perspectives, this shift indicates that the translators emphasize more on the game mechanics, the ludological aspects, instead of the game narrative, the narratological aspects. This shift does not imply the incompetence of the translators since this shift might occur due to (a) the problem of equivalence 
and (b) the absence of game aesthetics as a concern on VGT.

Ludology, a paradigm that places games as a game (Frasca 1999, 2007; J Juul 2001), and narratology, a paradigm that holds games as a form of narrative (Simons 2007; Sicart 2011), evoke a bipolar aesthetic relationship in game studies. These two paradigms, embodied through game mechanics and stories, are conflicting yet complementary features video games have. In VGT, translators should heed this game aesthetics since translation quality might suffer an ill assessment when certain Translation Quality Assessment (TQA) or Localization Quality Assessment (LQA) is applied to the translation products. Skillshot Lab's Notice Me Senpai, for instance, has an interesting translation in the perspectives of ludology and narratology. On one of the para-diegetic elements, the original game has $H A N G$ OUT WITH YOUR SENPAI! translated into Jalan dengan Senpaimu! The translation of hang out into jalanushers significant concern on its impact to the game aesthetics. Ludologically hang out and jalan imply linear conformity with the characteristics of an otome game that is to attract the attention of male characters through affection building since jalan still preserves the implied meaning of attraction and affection. Meanwhile from narratological perspectives, jalan generates dual referents namely (a) jalan referring to the act of having a quality time with the senpaiand (b) jalan referring to courtship status the senpai has with the avatar mediated player. These dual referents are absent from the original expression hang out as this expression refers to the first referent jalanimplies. The fact that Notice Me Senpai is played on mobile device, conventionally designed for leisure (Juul 2009), this aesthetics concern triggers less significance compared to console and PC games. This media consideration is what the translators might have concerned upon in regard to the above case.

The aforementioned four distinctive features as elaborated before signify that VGT studies, as a part of screen translation, require (a) translation studies to recognize shared similarities video game restrictiveness has with other restricted translation like film subtitling and comics translation, (b) studies on localization to unveil the roles, impacts, and significances localization holds toward VGT, (c) user's function to reveal how certain translation decision upon certain game assets influence the gamers in playing the game, (d) game studies to recognize the relationhsip between game translation and game aesthetics. This significance indicates that studies on VGT are inseparable from the studies on media, its users, and its aesthetics. This complementary condition implies that VGT studies are transtextual in nature and therefore, departing from this assumption, transtextuality, when employed for VGT study classification, might elicit a comprehensive classification on focuses VGT scholars might delve into, which is the objective of this research.

\section{TRANSTEXTUALITY AND VIDEO GAME Translation}

Aarseth (1997) through his masterpiece Cybertext: Perspectives on Ergodic Literature urges the necessity to consider the necessity of game studies, constructed and developed to study game aesthetics, since video games are a cybertext with distinctive features that defines itself. The status of cybertext video games bear signifies that video games are a transtextual product which incorporates cinematographic, poetic, prosaic, dramatic, and other literary elements from which their fusion generates a specific text true to itself, video games. Thereby, conjoining transtextuality in the discussion of video games is of 
necessity since video games themselves are manifested from other texts.

Transtextuality, as coined by Genette (1992), suggests that every text has a transtextual transcedence manifested and hidden in other texts. This transtextual transcendence is manifested through inter, para, meta, hyper, and archi relationships. In the case of video game translation, its intertextual relationship is visible from the necessity for video game translators to learn the game translation convention toward the translated games. Second, paratextual relationship, in the context of video games, appears on the presence of game manuals, game boxes, and other complementary materials for the game that require translations to assist the players in their play. These printed assets, as implied by O'Hagan \& Mangiron (2013), are as significant as the game itself though their status is a complementary element or companion for the game. Third, metatextual relationship is seen from the presence oftexton, texts not appearing on the game (Aarseth 1997) but appearing only to translators or to other than the translators through a specific device. Video game translators in translating the games work on text strings which are mechanical in nature and thereby, translation fallacy upon the strings might cause mechanical problems toward the game. This hidden nature of text strings is the essence of being a metatext in the scope of video game translation. Fourth, hypertextual relationship in video game translation concerns on the diverse in-game assets to which the translation is applied. These assets comprising of text, image, and image based text construct a hyperstructure to which a mode called traversal mode, specific procedures to access games are required (Aarseth 1997; Eskelin 2012). The necessity to traverse the assets in a proceduralist step constructs a hypertextual relationship game translators weave both as translators and gamers. The last, architextual relationship in video game context refers to the necessity for video game translators to adhere to game company's policies, legal issues, conventions and cultural concerns. The relationship between these five textualities constructs video game translation as a distinctive screen translation with transtextual transcendence power from which transtextuality defines the translation.

In regard to transtextual transcendence, each relationship as aforementioned has hegemonic power that attempts to dominate one another. To illustrate this assumption, the following example might help clarify it. Rockstar's Grand Theft Auto 3: San Andreas, for instance, suffers from fan localization through a modding system. Employing this system through the use of Self-Development Kit (SDK), the users can modify any graphical assets the game has. In this case, the game is not just translated but localized in a specific type of translation dubbed fan translation or fan localization. In the perspective of the hegemonic power of transtextual transcendence, this case tends to indicate that the architextual, the most subjective transcendence, might play the most dominant role since the translation is fan based which tends to operate on liking and disliking fashion.

In the perspectives of VGT studies, transtextuality, due to the power of its transtextual transcendence, exposes the studies toward different textual forms from which the studies are classifiable based on the presence of different texts intertwined with VGT. The following example might help understand how VGT studies are of necessity to examine through the perspectives of transtextuality. Altermyth Pandawa's Throne of Demons, for example, translates every diegetic elements of the game including weapons, armors, accessories, and other paraphernalias. The decision is proven to be mistaken 
and this condition leads to criticisms as shared by Monica (2015). The translation of Throne of Demons ignores the convention of MMORPG translation in Indonesia in which the names of paraphernalia elements as mentioned before are not translated, only the description is translated. This decision might be intertwined with the company policy and departing from this policy, a convention on paraphernalia elements of MMORPG is violated. Aesthetically this decision also influences the shifts on luden if perceived from ludological and narratological perspectives. Throne of Demons case, if viewed from VGT studies, is analyzable through different textual transcendence namely (a) translation decision making from Munday (2012), for example, in relation to (b) the transcreation Mangiron \& O'Hagan (2006; 2013) exercised by Altermyth Pandawa with a concern on (c) the shift of luden (Purnomo et al. 2016) Throne of Demons might suffer from (d) in the mechanics oriented (Clearwater 2011) Multiplayer Online Battle Arena (MOBA) featured MMORPG. This example indicates that the VGT of Throne of Demons is studiable from certain theories of translation studies, cultural studies, game aesthetics, and media studies. This transtextual relationship between the four studies in regard to VGT denotes the possibilities to classify VGT studies based on its relationship with otherstudies. Departing from this consideration, VGT studies are classified into transversality, transcreation, transfiguration, and transmediation. The following section will clarify its classification.

\section{Transversality and the Position of Translation Theories}

Transversality roots from mathematics term referring to the intersection of spaces. We propose this term to signify VGT studies that emphasize on the intersection between translation theories and VGT. Studies under this classification focus on how certain theories of translation provide theoretical basis in a response to certain issues in VGT. Studies by Merino (2008;2014), Fernández Costales (2012), for instance, highlight the necessity to incorporate translation strategies in responding the challenges video game localization exposes. In this study type, translation theories emerging from nonvideo game translation study are utilized as a theory basis to address certain issues VGT offers with an assumption that VGT is a part of translation studies. Therefore, employing certain translation theories onto VGT issues is assumed to display an understanding on how translation theories might elicit comprehension toward certain VGT phenomenon. Since the focus taken is the relationship between translation theories and VGT, this type of study tends to ignore the fact that the term VGT is inseparable from its more widely used term, video game localization.

Executing this study, potential researchers would have to first specify VGT issues considered to display a linkage to certain translation theories. In Square Enix's Final Fantasy Awakening, for instance, the game translation demonstrates inconsistencies in Role Playing Game (RPG) terminologies. The Indonesian version preserves most interface menus in English but translating some of the menu like attack into serang. One of translation theories deemed to fit in responding this phenomenon is translation ethics as articulated by Venuti (1998). Applying this theory on the VGT of Final Fantasy Awakening, researches might reveal the consideration the translators take in preserving the ethics of RPG term translation convention and the quality of the interface translation.In revealing the quality, to strengthen the roles of translation theories, translation quality assessment by Nababan \& Nuraeni (2012) in tandem with translation techniques by Molina \& Albir (2002) 
might be applied. RPG term translation inconsistencies might be analyzable also from the theories of translation consistencies from Merkel $(1996,1998)$ and Moorkens \& Doherty (2014). Applying these theories, scholars are required to observe the translators' attitudes toward a certain translation project and their aptitude in maximizing the use of translation memory tools. Combining this scheme with the previous study on ethics and quality, a thorough finding on the reasons backgrounding the inconsistencies found from Final Fantasy Awakening might be comprehensively elucidated since product and process oriented analyses are applied. Treating the inconsistency issues of Final Fantasy Awakening translation as such, the study might reveal how the link between inconsistency, translation techniques, and translation quality under the umbrella of translation ethics.

The aforementioned link is the essence of transversality with translation theories of inconsistencies and ethics of RPG terms being the intersected elements. Studies resulting from transversality is expected to indicate transtextual transcendence of the intersected elements. By transtextual transcendence indicates that the intersection might usher a new point of departure in conducting further studies in regard to the previous transtextual relationship. In the case of term translation inconsistencies Final Fantasy Awakening displays, further studies are executable with translation ethics and inconsistencies as the point of departure, designing a model to cope the problems of term inconsistency in video games, for instance. This model is designable when this study heeds the findings obtained from the intersection of inconsistency, translation techniques, and translation quality in the context of translation ethics.

\section{Transcreation and the Implied Messages of Game Mechanics}

The necessity to loan the term transcreation, a creative adaptation on both words and meaning (Pedersen 2014), is due to specific traits transcreation carries, as mentioned before, namely the needs to concur to target market while pertaining gaming experiences elicited from game mechanics. Transcreation, on this paper, is a term referring to VGT studies which emphasize on discussing culture related issues in regard to game mechanics with transcreation theories as the umbrella. Studies like onomastics translation in video games as illustrated by Mangiron \& O'Hagan on Final Fantasy X-2 case (2006), on Mangiron on Final Fantasy IX(2007), on Purnomo on Lightning Returns: Final Fantasy XIII (2015), and other onomastics related problems. On the three Final Fantasy titles, the translators decide to alter the names of equipments and characters to adjust the local culture of the target market. In Final Fantasy $X$-2, a sword by the name kachofugetsu literally meaning 'flower, bird, wind, moon' is translated into painkiller. In Final Fantasy IX, the main character by the name Zidane is localized into Jitan when sold in France to avoid legal issues with the footballer Zinedine Zidane. In Lightning Returns: Final Fantasy XIII, the costumes of Lightning, the main character, are dominantly localized. For instance, seintodamuzeru, transliterated into Saint Damsel, is localized into School's Out. This onomastics localization, besides being culturally influenced, is the impact of the game mechanics with spatial constraints being the primary issue.

Booya Interactive's Booya Texas Poker, for instance, suffers also an onomastics problem regarding with card name. In the English version, the name for the player's cards is hole card translated into kartu tangan in bahasa 
Indonesia. The assumption emerging from this translation is that the translator refers more on the cultural habit on playing cards in which the players almost always hold the cards. Meanwhile, the naming of hole cards might refer to the strategy construction by peeking at the cards while kartu tangan. Regarding with the game mechanics, to bridge this cultural concern, the translators have to consider the character number constructing the name kartu tangan, which exceeds the number of the original name by two. To do so, image based font is selected to avoid any textual errors in the mechanics. If this case is analyzed, it will be categorized into transcreation classification since a relationship between localization and game mechanics concerns occur. In executing the study, first, the scholars are required to be knowledegable on gambling culture in the source and target culture. Journal of Gambling Studies might be an assistive resource in this matter as it discusses scientifically the culture and aesthetics of gambling. Second, game mechanics and assets influenced by the translation are examined. In the case of Booya Texas Poker translation, the translation is typefaced in image format enabling it to cope with the spatial constraints. This decision is mechanically acceptable as the translation of hole cards appear on tutorial assets which require a detailed description to play the card game. This acceptability indicates that certain localization oriented translation might generate positive impacts to certain game assets through a thorough examination on the game mechanics.

In relation to the intersection power transversality has, transcreation is of intercession implying that, in VGT perspectives, studies classified into transcreation positions cultural issues and VGT as power holders standing on an equal ground without any hegemonic power influencing each other. This intercession power indicates that depending on the issues taken, cultural issues might be of dominant over VGT and vice versa. In regard to the cultural issues, studies under transcreation classification umbrella poses weaknesses on the diverse meaning of culture and its overlapping meaning with mechanics. Poker, for instance, has the same mechanics though it is adapted into electronic or digital format. When this similarity is preserved, formula appears. If the formula is preserved, a convention emerges. Then, this convention might lead to the appearance of Poker gambling culture which might refer to how the game is played on different media. Thus, mechanics is a culture of its own, to some extent. Different from transversality which shares two different objects yet part-to-whole in nature, culture which becomes the focus of transcreation is rich in nature and thereby requiring specific focus from which specific focus on game mechanics should also be addressed.

\section{Transfiguration and the Transferability of Game Aesthetics}

When it comes to game aesthetics, it mostly refers to the game studies and its significance in VGT domain. This significance is hinted by Deming in O'Hagan and Chandler's interview (2016) implying that if concerns on game studies are incorporated into VGT, demarcated border between the two fields would be lessened. In other words, possibilities in the emergence of intertwined new domain and discussion from the conjoined two studies are open and implying that a process of transfiguration takes a role in the emergence. Studies by Mandiberg (2015) for instance, highlights how language assumes less important role than rule, narrative, play, and context. This condition implies, in regard to VGT, that even linguistics need to be adjusted to game aesthetics and vice versa when both are under highlight. In VGT, linguistics units are mostly existent in text strings and thereby 
treating text strings as the way we treat linguistics units in a real life would be, to some extent, misleading. In relation to transfiguration, literally implying the restructurization of object, studies under this classification, as hinted before, focus on the interactions between VGT and game aesthetics.

In Nexon's Kart Rider Online, a cartoon based MMO Racing Game, the game aesthetics revolve around racing related mechanics, rules, and experiences combined with RPG aesthetics like power ups, items, weapons, and fantasy universe. This hybrid cross genre is presented in an online mode in which players around the globe could compete for a trophy. The presence of three different aesthetics namely racing game, RPG, and online game indicate that (a) the game aesthetics has a focus not only on racing but strategy building to defeat the enemies and (b) the target market is assumed hailing from racing and RPG gamers. In relation to transfiguration, this hybrid cross genre aesthetically has reflected the transfigurative part of the game from which transfiguration in VGT should be applied as a response to this hybrid status. To do so, first, a specific focus of game aesthetics is selected. In the case of Kart Rider Online, gameplay instructions delivered through description are open for a discussion since the essence of racing and strategy making relies on (a) mechanical elements more than on narrative elements and (b) game accessibility procedures. Employing the theories of game aesthetics, proceduralism (Trenor et al. 2011) for instance, the original procedures to play the game articulated through tutorials and descriptions, mechanically constructed on interface, are examined. Done with the examination, the translated versions of tutorials and descriptions are examined to reveal whether the translators tend (a) to focus on the game message to deliver the game mechanics, (b) on the spatial rules, or (c) on the balance presentation of both elements. To execute this fashion, VGT theory discussing about the relationship between game aesthetics and translation such as Dietz (2012), Sajna (2013), and Purnomo et al. (2016) are applied. Either result revealed, a gamer response or interaction based theory like selfperception theory in game (Klimmt, Hefner \& Vorderer 2009) or HumanComputer Interaction system value Barr and Biddle (2006). Employing these theories, a finding showing how the gamers respond and interact toward the translated version of the tutorials and descriptions with interface as the concern would be revealed. This interaction between game aesthetics and VGT theories is the point of being a transfiguration classification since the merger between those theories indicates complementary and mutual relationship.

Transfiguration is different from transversality with the former relying on intersection and the latter on interaction. In intersection, one element over dominates the other elements. Transversal VGT studies emphasize on how translation theories could address phenomena occuring on VGT. Meanwhile, interaction two elements have similar power to influence one another and thereby, as shown from the example above, game aesthetics and VGT stand on the same ground from which their interaction might address and shape certain phenomena occuring on both fields. In relation to transcreation which is intercession in power, transfiguration fundamentally shares similar trait regarding with the fact that two elements applied for the study standing on the same ground. The difference is that in interaction, the two elements naturally attempt to influence one and another while in intercession, the two elements will not influence one another if they are not made so. 
Transmediation and the Concerns on Media

Bassnett (2013) urges the necessity to have new media translation, from which translation has to adhere the studies and distinctive features of new media, encompassing linguistic, paralinguistics, and extralinguistic elements embodied through words, sounds, and images (Werner 2001). This urgency, in screen translation perspectives, ushers an important consideration toward the media to which translation is applied since the text of new media serves two functions namely as the text itself and a metalanguage for the media (Manovich 2001). Screen translations with VGT as its type are required to address and to adhere these two functions of new media and thereby treating screen translations from the perspectives of translation studies only is inadequate. Treating screen translations from translation study perspectives only touches the function of new media as a text not as a metalanguage and in order to cope the metalanguage function, studies on the media to which the translation is applied should be concerned.

Zynga's FarmVille 2: Country Escape, translated into FarmVille 2: Wisata Desa (lit. Village Tourism), is an Android game, a sequel to the famous Facebook game FarmVille. Different game platform FarmVilleis designed to signifies different aesthetics and user's functions. These differences, in the case of VGT, are well addressed by Zynga. This is visible from their orientation on localization as seen, for example, from the title translation and its preference for koperasi in Gabung Koperasi Pertanian dan Bertransaksi dengan Temanas an exchange for co-op in Join a Farm Co-Op and Trade with Friends. The word $\mathrm{Co}-\mathrm{Op}$ narratively refers to the presence of store like transaction place in the game while at the same time mechanically functions as trading place. This function indicates that $\mathrm{Co}$ -
$O p$ textually exists as a store but metalingually the word refers to a game term meaning that players could cooperate each other in a competitive fashion. Interestingly the translators attempt to pertain the sense of being $\mathrm{Co}-\mathrm{Op}$ by word-playing it with op in Koperasi. This attempt indicates that the translators are aware of video game metalanguage from which game aesthetics is constructed. In term of mediating between textual and metalanguage function, the translators utilize image based font with a modification on the font size. Doing so, the translators could deliver the op case and also transfer the essence of trading, translated into transaksi. This case also points out that the translators are profound and proficient on comprehending the features of the different media to which the game is designed and holding on the media features, the translators could negotiate between the translation, textual and metalanguage functions.

VGT studies under transmediation, as discussed above, revolve around (a) the comparison oftranslationfrom similar games but ported to or designed for different game media, (b)the challenges game platforms trigger in regard to VGT, and (c) strategies to mediate between textual and metalingual functions. These study types are linked by intermediation power, in which the influence VGT or game media has is transferred to each other to share the benefits each study has. This intermediation, though sharing hegemonic power as interaction, displays differences on the fact that the hegemonic power is not to overpower each other but to share the positive sides of the hegemonic power.

\section{Conclusion}

Transtextuality, due to its linear nature to VGT under the umbrella of GILT, is applicable as a basis to design a classification of VGT studies. Applying transtextuality on VGT studies enables VGT scholars to devise 
the topics they attempt to analyze by recognizing the characteristics of each classification. Four classifications are constructed with the power of transtextual transcendence as its pillars. They are transversality, transcreation, transfiguration, and transmediation.

First, transversality refers to VGT studies that emphasizes on the incorporation of translation theories to address VGT issues. Departing from these characteristics, studies on VGT quality, ideology, and approach are executable with translation theories as the axis of the study. This position as axis indicates that VGT is treated as a passive object with translation theories as the active subject. This power translation theories display before VGT, in tranversality classification, is of intersection. In studies with intersection characteristics, the goal is to reveal the spots where intersection takes place. In the context of VGT, the spots revealed would strengthen the roles of translation to address translation domains which seem to be less analyzable from translation theory perspectives.

Second, transcreation concerns on VGT studies focusing on cultural issues and their relationship, especially negotiative relationship, with game mechanics. Taking this classification, studies on how translation evokes impacts on game configuration such as button or keypad adjustment, on onomastics linearity with the game object attributes, on the explorative functions of certain tutorials, and on other game mechanics are of possibilities to study. Unlike transversality which emphasizes on revealing the intersected spots of two elements with one being more overpowered than the other, the two elements of transcreation namely VGT and game mechanics have similar hegemonic power. Depending on what issues the scholars attempt to discuss, one of the elements could be more dominant and influential over the other element. Thereby, VGT studies under this classification could be leaning more on VGT as the axis or vice versa.

Third, transfiguration highlights the necessity to consider the relationship of game aesthetics with VGT. Studies executed under this classification seeks the possibilities of a shift in game assets as a result of the translation process, the shift on gaming experience as an impact of certain translation strategies and decisions, the influences and roles of ludology and narratology in the process of translation, and other impacts on game aesthetics and translation related topics. In transfiguration, due to its power of interaction, studies resulting from this classification tend to signify its roles and influences one another and thereby, game aesthetics might leave a mark of significance upon VGT and vice versa.

Fourth, transmediation concerns on the relationship between VGT and the media to play the games. VGT studies under this umbrella yield discussions over whether different media influences the translation quality of certain video games, whether textual and metalingual functions are synchronically delivered in the translated games, whether media porting generates certain impacts to the emergence of translation strategies and decisions, and other discussions related the relationships between media types, features, ports, accessibilities, and functions with VGT. The intermediation power transmediation has signifies the necessity of each element to complement the other. Thereby, the study focus is not one of the two elements but it comprises both elements since textual and metalingual functions are present within each element.

\section{REFERENCES}

Aarseth, EJ. 1997. Cybertext: Perspectives on Ergodic Literature. JHU Press 
Barr, P, J. Noble \& R. Biddle. 2006. "Video game Values: Human-computer Interaction and Games". Interacting with Computers, 19 (2): 180-195.

Bassnett, S. 2013. Translation Studies. New York: Routledge

Bernal-Merino, M. 2008. "Training Translators for the Video Game Industry". The Didactics of Audiovisual Translation. Ámsterdam/Filadelfia: John Benjamins: 141-156

Bernal-Merino, MÁ. 2014. Translation and Localisation in Video Games: Making Entertainment Software Global. Routledge

Cadieux, P \& B. Esselink. 2004. "GILT: Globalization, Internationalization, Localization, Translation". Globalization Insider, 11 (1.5): 1-5

Calvillo-Gámez, EH, P. Cairns \& AL. Cox. 2015. "Assessing the Core Elements of the Gaming Experience. In Game User Experience Evaluation: 37-62. Springer International Publishing

Chandler, HM \&SOM.Deming, 2011. The Game Localization Handbook. Jones \& Bartlett Publishers

Christoph, K, H. Dorothée, \& V. Peter, 2009. "The Video Game Experience as 'True' Identification: A Theory of Enjoyable Alterations of Players' Selfperception". Communication Theory, 19 (4): 351-373

Clearwater, D. 2011. "What Defines Video Game Genre? Thinking about Genre Study after the Great Divide". Loading..., 5 (8)

Dietz, F. 2007. "How Difficult Can That Be?": The Work of Computer and Video Game Localization". Tradumàtica: Traduccióitecnologies de la Informaciói la Comunicació, (5)

Eskelinen, M. 2012. Cybertext Poetics: The Critical Landscape of New Media Literary Theory. Bloomsbury Publishing

Fernández Costales, A. 2012. "Exploring Translation Strategies in Video Game Localisation". MonTI. Monografías de Traducción e Interpretación, (4).

Frasca, G. 1999. "Ludology Meets Narratology: Similitude and Differences between (Video) Games and Narrative". Ludology.org
Frasca, G. 2007. Play the Message: Play, Game, and Video Game Rhetoric (Unpublished $\mathrm{PhD}$ dissertation) Copenhagen: IT University of Copenhagen

Genette, G. 1992. The Architext: An Introduction (31). Los Angeles: Univ of California Press

Hjorth, Larissa. 2011. Games and Gaming. New York: Oxford.

Jacobs, Dale. 2014. Design, Arthrology and Transtextuality in Seagle's and Kristiansen's It's a Bird, 5 (2): 361

Juul, J. 2001. "Games Telling Stories".Game Studies, 1 (1), 45

Juul, J \& AC. Revolution. 2009. Reinventing Video Games and Their Players.

Mandiberg, S. 2015. Responsible Localization: Game Translation Between Japan and the United States. San Diego: University of California

Mangiron, C \& M. O’Hagan. 2006. Game Localisation: Unleashing Imagination with 'Restricted' Translation. The Journal of Specialised Translation, 6: 10-21

Manovich, L. 2001. The Language of New Media. Massachussetts: MIT Press

Merino, MB. 2006. "On the Translation of Video Games". The Journal of Specialised Translation, 6: 22-36

Merkel, M. 1996. "Checking Translations for Inconsistency: A Tool for the Editor". In Proceedings of the Second Conference of the Association for Machine Translation in the Americas (AMTA-96): 157-167

Merkel, M. 1998. "Consistency and Variation in Technical Translation: A Study of Translators' Attitudes" . Unity in Diversity: 137-149.

Molina, L. \& A. Hurtado Albir. 2002. Translation Techniques Revisited: A Dynamic and Functionalist Approach. Meta: Translators' Journal, 47 (4): 498-512.

Monica, G. 2015, June 30. A Five-Minute Guide to Indonesia's Mobile Game Market. Retrieved September 20, 2017, from <http://www.oneskyapp.com/blog/ indonesia-mobile gaming/>

Moorkens, J, S. Doherty, D. Kenny \& S. O'Brien. 2014. "A Virtuous Circle: Laundering Translation Memory Data 
Using Statistical Machine

Translation”. Perspectives, 22 (3): 291303

Munday, J. 2012. Evaluation in Translation: Critical Points of Translator Decision-making. New York: Routledge

Nababan, M \& A. Nuraeni, 2012. "Pengembangan Model Penilaian Kualitas Terjemahan”. Kajian Linguistik dan Sastra, 24 (1)

O’Hagan, M. 2005. "Multidimensional Translation: A Game Plan for Audiovisual Translationin the Age of GILT". Proceedings of the Marie Curie Euroconferences MuTra' Challenges of Multidimensional Translation'. Saarbrücken, 2-6 May 2005: 76-87

O'Hagan, M \& C. Mangiron. 2013. Game Localization: Translating for the Global Digital Entertainment Industry(106). Amsterdam: John Benjamins Publishing

O’Hagan, M \& H. Chandler, 2016. "Game Localization Research and Translation Studies". Border Crossings: Translation Studies and Other Disciplines, 126: 309

Pedersen, D. 2014. "Exploring the Concept of Transcreation: Transcreation as More than Translation". Cultus: The Jos Isournal of Intercultural Mediation and Communication, 7 (57):71

Purnomo, SLA. 2015. "Grab the Garb: The Influences of Translation Techniques in theLudological Aspects of Video Game Translation (A Case Study of Square
Enix'sLightning Returns: Final Fantasy XIII)”. Izumi, 4 (1): 1-9

Purnomo, SLA, M. Nababan, , R. Santosa \& D. Kristina. 2016. "Game Time: Revisiting Ludic Linguistics for Video Game Analysis". Prosiding Prasasti: 689-694

Purnomo, SLA, M. Nababan, R. Santosa \& D. Kristina, 2016. "Ludic Translation: The Problems of Game Asset Transferability in Video Game Translation”. ICOLTS Proceedings: 328335

Treanor, M, B. Schweizer, I. Bogost \& M. Mateas. 2011, June. "Proceduralist Readings:How to Find Meaning in Games with Graphical Logics". In Proceedings of the $6^{\text {th }}$ International Conference on Foundations of Digital Games: 115-122. ACM

Sajna, M. 2013. "Translation of Video Games and Films: A Comparative Analysis of Selected Technical Problems". Poznań: Polskie Towarzystwo Badania Gier, 5: 219-232

Sicart, M. 2011. "Against Procedurality”. Game Studies, 11 (3): 209

Simons, J. 2007. "Narrative, Games, and Theory". Game Studies, 7(1):1-21

Venuti, L. (1998). The Scandals of Translation: Towards an Ethics of Difference. Taylor \& Francis US

Werner, JR. 2001. "Text and Context in Multimedia Translation”.Benjamins Translation Library, 34: 51-64. 